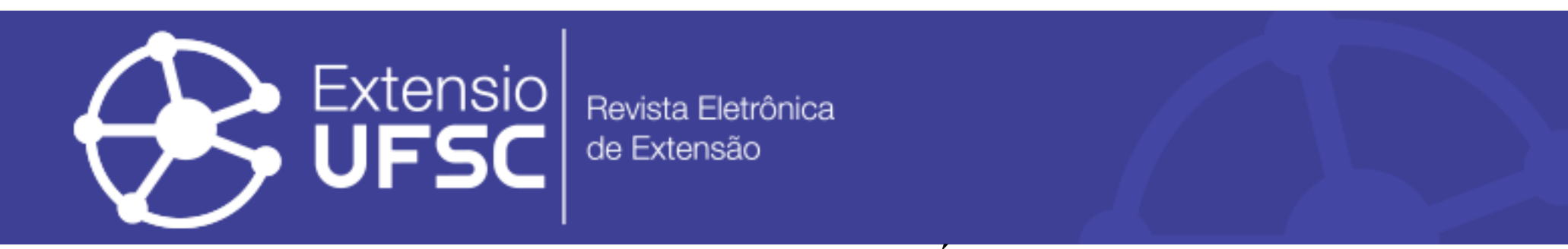

\title{
TRANSTORNOS DOLOROSOS NOS PÉS EM IDOSAS: PESQUISA- CUIDADO NO CONTEXTO DE ATIVIDADE EXTENSIONISTA
}

\author{
Maria Cecilia Da Lozzo Garbelini \\ Faculdades Pequeno Príncipe \\ ceciliagarbelini@hotmail.com \\ Leide da Conceição Sanches \\ Faculdades Pequeno Príncipe \\ leide.sanches@fpp.edu.br \\ Karyna Turra Osternack \\ Faculdades Pequeno Príncipe \\ karyna.osternack@fpp.edu.br
}

Patrick Alves dos Santos

Faculdades Pequeno Príncipe patrickalvesbio@gmail.com

Ivete Palmira Sanson Zagonel

Faculdades Pequeno Príncipe ivete.zagonel@fpp.edu.br

Franciele Coutinho França Faculdades Pequeno Príncipe framnutri2011@hotmail.com

\section{Resumo}

Pesquisa que objetiva identificar os transtornos dolorosos nos pés em um grupo de idosas e promover ações de conscientização em saúde sobre a temática, otimizando comportamentos e hábitos de vida. Trata-se de um estudo descritivo, com abordagem quantitativa, realizado pela utilização do Arco de Maguerez, com enfoque na pesquisa-cuidado e uso do instrumento denominado Índice Manchester de Incapacidade Associada ao Pé Doloroso no Idoso. Os resultados apontam que a maioria das participantes tem cuidado com os pés e com os sapatos, realiza as atividades laborais e poucas se declaram impedidas de praticar o lazer. Observa-se que o processo de envelhecimento é marcado por modificações fisiológicas e patológicas ocasionando mudanças físicas, psicológicas e sociais. Conclui-se que a incapacidade funcional dos pés das participantes da pesquisa é baixa e que as ações extensionistas articuladas com a comunidade fortalecem os atos de aprender a aprender e, dessa maneira, formar profissionais de saúde e cidadãos mais conscientes de sua saúde.

Palavras-chave: Idoso; Pés; Autocuidado; Educação em Saúde; Extensão Comunitária.

\section{PAIN DISORDERS IN THE ELDERLY FEET: CARE RESEARCH IN THE CONTEXT OF EXTENSION ACTIVITY}

\section{Abstract}

Research that aims to identify painful foot disorders in a group of elderly women and promote health awareness actions on the subject, optimizing behaviors and lifestyle habits. This is a descriptive study with a quantitative approach, carried out using Arco de Maguerez, focusing on care research and the use of the instrument called Manchester Index of Disability Associated with Painful Foot in the Elderly. The results show that most participants are careful with their feet and shoes, perform work activities and few declare themselves prevented from practicing leisure. It is observed that the aging process is marked by physiological and pathological changes causing physical, psychological and social changes. It is concluded that the functional incapacity of the feet in the research participants is low and that extension actions articulated with the community strengthen the acts of learning to learn and, in this way, train health professionals and citizens who are more aware of their health.

Keywords: Elderly; Feet; Painful Feet in Elderly; Health Education; Extension Activity.

\section{TRASTORNOS DE LOS PIES DOLOROSOS EN ANCIANOS: INVESTIGACIÓN- ATENCIÓN EN EL CONTEXTO DE ACTIVIDAD DE EXTENSIÓN}

\section{Resumen}

Investigación que tiene como objetivo identificar los trastornos dolorosos del pie en un grupo de mujeres mayores y promover acciones de concienciación sanitaria sobre el tema, optimizando comportamientos y hábitos de vida. Se trata de un estudio descriptivo con abordaje cuantitativo, realizado con Arco de Maguerez, centrado en la investigación asistencial y el uso del instrumento denominado Índice de Manchester de Discapacidad Asociada con Pie Doloroso en el Anciano. Los resultados muestran que la mayoría de los participantes tienen cuidado con los pies y los zapatos, realizan actividades laborales y pocos se declaran impedidos para practicar el ocio. Se observa que el proceso de envejecimiento está marcado por cambios fisiológicos y patológicos provocando cambios físicos, psicológicos y sociales. Se concluye que la incapacidad funcional de los pies en los participantes de la investigación es baja y que las acciones de extensión articuladas con la comunidad fortalecen los actos de aprender a aprender y, de esta manera, formar profesionales de la salud y ciudadanos más conscientes de su salud.

Palavras clave: Anciano; Pies; Autocuidado; Educación para la Salud; Alcance Comunitario. 
Transtornos dolorosos nos pés em idosas: pesquisa-cuidado no contexto de atividade extensionista

\section{INTRODUÇÃO}

A educação em saúde com perspectiva transformadora prescinde da formação de professores capazes de propor intervenções condizentes com as realidades e suas especificidades. O ensino, a pesquisa e a extensão fazem parte do processo de ensino e aprendizagem e compõem o eixo fundamental das Instituições de Ensino Superior (IES), o qual não pode ser compartimentado. É pelas atividades de extensão que as IES desempenham seu papel de aproximação da realidade, o que se evidencia neste estudo, conciliando o ensino e a pesquisa por meio da inserção na comunidade em questão.

O presente estudo faz parte das atividades de extensão desenvolvidas pelo projeto de extensão Educar para Prevenir, de IES filantrópica, em exercício ininterrupto desde 2009, com objetivo de realizar comunicação em saúde nas escolas e comunidades parceiras. Isto porque a formação do profissional de saúde, para o exercício de saúde humanizada, pressupõe a inserção do estudante na comunidade desde o início da sua formação.

Nesta perspectiva, torna-se imprescindível o desenvolvimento de ações junto à comunidade de forma a perceber melhor a realidade e, por meio desta, construir e ressignificar saberes, a partir da valorização do conhecimento popular. O intercâmbio de conhecimentos permite maior envolvimento com as questões sociais e o desenvolvimento de ações de promoção da saúde a partir de um prisma holístico, onde as diversas visões de mundo passam a ser respeitadas. Este é o sentido da natureza multidimensional do ser humano, que aponta para uma educação promotora de inteligência geral, a qual torna as pessoas aptas para compreender a realidade complexa (MORIN, 2001).

A educação em saúde como prática libertadora se dá pela aproximação da realidade, mas não é qualquer aproximação, e sim a que se faz de maneira crítica, é a experiência crítica e não ingênua, que consiste na tomada de consciência. A consciência crítica da realidade leva, portanto, à busca de mecanismos de aproximação desta, pois a consciência dos problemas reais só é possível a partir do próprio contexto onde se pretende trabalhar. Este é o compromisso histórico que não pode ser desassociado do conhecimento técnico e teórico, pois estes só existem e fazem sentido a partir dos problemas reais (FREIRE, 1980).

O desafio consiste em não só levar as informações em saúde, mas torná-las reflexivas, sendo este o propósito do projeto em questão, de planejar e promover ações por meio da comunicação em saúde, a partir do levantamento dos problemas pela própria comunidade, visando atender às suas reais necessidades. Neste contexto, esta atividade de extensão visou apreender informações junto aos idosos sobre o cuidado com os pés, por meio da inserção na 
Transtornos dolorosos nos pés em idosas: pesquisa-cuidado no contexto de atividade extensionista

comunidade, e identificar os transtornos dolorosos nos pés desses idosos pela aplicação de questionário, para levantamento de dados.

Pesquisa feita por Marques et al. (2019) aponta que a realização das intervenções educativas, em uma abordagem grupal, mostrou melhoria quanto ao cuidado com os pés. Ainda, estudo realizado por Silva e Santos (2020) destaca que a roda de conversa, com a utilização de figuras ilustrativas e folhetos sobre os cuidados com os pés, foi um método de ensino essencial para debater sobre a temática, já que os participantes se sensibilizaram sobre o assunto e perceberam a necessidade da adoção de práticas de autocuidado à prevenção de doença. Os autores Silva, Santo e Chibante (2017) relatam que estratégias educativas implementadas pelo uso de cartilhas e o uso de protocolos podem colaborar para minimização do problema, por permitir acesso a informações que favorecem a avaliação e prevenção de dificuldades nos pés e a instalação de incapacidades e complicações decorrentes das mesmas.

Para países em desenvolvimento, como o Brasil, o envelhecimento populacional representa cada vez mais desafios tanto na área social, quanto na econômica (SILVA, SANTO; CHIBANTE, 2017). Segundo Damaceno e Chirelli (2019), o crescimento da população idosa brasileira tem trazido desafios à sociedade, em termos econômicos, previdenciários, de infraestrutura urbana e de serviços.

Observa-se que o Brasil ocupou em 2015 a sétima colocação mundial em número de idosos e as projeções mostram que, possivelmente, o Brasil ocupará a sexta posição em 2025 (FERNANDES et al., 2013). Com a maior concentração de idosos na população, observou-se aumento na incidência de doenças crônicas não transmissíveis, que podem ser acompanhadas por sequelas, as quais limitam o desempenho funcional e geram dependência. A presença de múltiplas doenças com diferentes níveis de gravidade pode influenciar o desempenho das atividades da vida diária, levar a um estado de fragilidade e diminuir a autonomia dos idosos (TAVARES, 2012).

Há consenso geral de que as mulheres desenvolvem e relatam mais problemas nos pés do que os homens. Isto pode ser atribuído à influência dos calçados inadequados que aumentam a chance de desenvolvimento de problemas nos pés que prejudicam a capacidade funcional (FERRARI et al., 2012). Tais dados são próximos ao estudo feito por Silva, Santo e Chibante (2017) identificando que a população mais jovem usa calçados inadequados por modismo e estética, a despeito do conforto e da segurança. Contrária à população mais jovem, os idosos tendem a usar calçados inadequados, principalmente, porque buscam conforto, ainda que em prejuízo à segurança. Outro aspecto, segundo Gorecki (1978), é a tolerância à dor, visto que as mulheres relatam sentir mais dores que os homens e, consequentemente, procuram mais pelos serviços de saúde. 
Transtornos dolorosos nos pés em idosas: pesquisa-cuidado no contexto de atividade extensionista

Os pés dolorosos podem oferecer prejuízos adicionais para a saúde dos idosos, compondo um sério problema para o envelhecimento. Para o paciente geriátrico o cuidado com os pés constitui um grande desafio, uma vez que pode detectar problemas causadores de incapacidade nessa faixa etária. Ao longo da vida, as modificações que advêm dos pés podem ser decorrentes de doenças sistêmicas, perturbações de marcha, maus-tratos ou traumatismos podais (COUTO et al., 2014).

A partir das reflexões acima, o presente estudo justifica-se pela necessidade de ampliar o conhecimento acerca das alterações podais na população idosa e sua associação com a incapacidade funcional que acarreta diminuição da autonomia e da qualidade de vida dessas pessoas.

Assim, por meio de atividade de extensão na comunidade, que permitiu maior aproximação com grupo de idosas, se realizou a pesquisa e a ação em saúde. Observou-se a necessidade de trabalhar com o problema de pés dolorosos, e delineou-se os objetivos para identificar os transtornos dolorosos nos pés em grupo de idosas e promover ações de conscientização em saúde sobre a temática, otimizando comportamentos e hábitos de vida com a inclusão do ritual de lava-pés

\section{MATERIAIS E MÉTODOS}

Trata-se de um estudo descritivo, com abordagem quantitativa, com utilização Arco de Maguerez e enfoque na pesquisa-cuidado. Participaram 75 idosas com idade igual ou superior a 60 anos e, para investigar a frequência de incapacidade funcional associada às dores nos pés, foi utilizado o Manchester Foot Pain and Disability Index (MFPDI) - Índice de Manchester de incapacidade associada ao pé doloroso no idoso, descrito na $3^{\text {a }}$ etapa da pesquisa-cuidado.

A pesquisa-cuidado busca a conexão entre método e cuidado, não oferecendo ao método o foco central da interação, mas, sim, ao sujeito pesquisado em sua total essência. Não é apenas ativar o desvelamento e as descobertas por meio do método, mas é um acender a luz dentro do ser, focalizando suas possibilidades, sua existência e a essência da experiência (NEVES e ZAGONEL, 2006). As etapas que compõem o método de pesquisa-cuidado incluem: a) aproximação com o objeto de estudo; b) encontro com o ser pesquisado-cuidado; c) estabelecimento das conexões de pesquisa, teoria e prática; d) afastamento do ser pesquisadocuidado. e) análise do apreendido (ZAGONEL et al., 2016).

A problematização pelo Arco de Maguerez (Figura 1 - Representação gráfica do Arco de Maguerez) iniciou pela observação da realidade seguida pelo levantamento dos Pontos-chaves, 
pela teorização e aplicação de questionário, pelas hipóteses de solução, e, por fim, pela aplicação à realidade. A metodologia da problematização foi facilitadora e permitiu orientar o trabalho como um todo no âmbito proposto - do ensino, da pesquisa e da extensão, como elementos indissociáveis e necessários para a prática profissional humanizada.

Figura 1 Representação gráfica do Arco de Maguerez

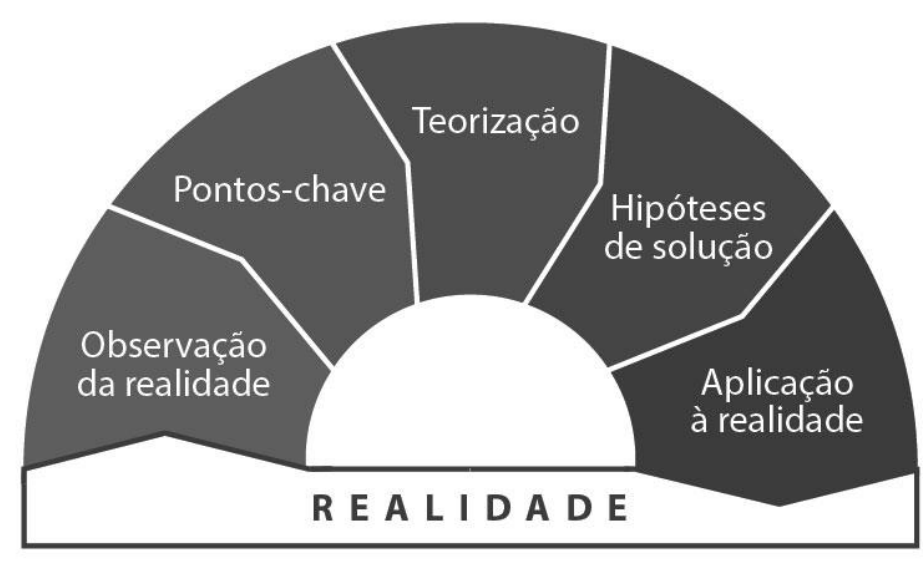

Fonte: Ogradowski et al., 2018.

A Figura 1 permite a visualização das etapas percorridas para a construção do trabalho, que permitiram o reconhecimento da realidade por meio da qual se tornou possível tomar consciência dos problemas relacionados à temática apontados pelo grupo de idosas. Esse trabalho possibilitou aos estudantes e profissionais de saúde, participantes do projeto de extensão, a elaboração de estratégias de aprimoramento da comunicação em saúde.

Ao entrelaçar a pesquisa-cuidado com o Arco de Maguerez foi possível estabelecer o caminho do cuidado e da apreensão das informações e dos dados para a pesquisa (Quadro 1 Articulação da pesquisa-cuidado e Arco de Maguerez).

Quadro 1 - Articulação da pesquisa-cuidado e Arco de Maguerez

\begin{tabular}{|l|l|}
\hline \multicolumn{1}{|c|}{ Pesquisa-Cuidado } & \multicolumn{1}{|c|}{ Arco de Maguerez } \\
\hline Aproximação com o objeto de estudo & Observação da realidade \\
\hline Encontro com o ser pesquisado-cuidado & Pontos-chaves \\
\hline $\begin{array}{l}\text { Estabelecimento das conexões de pesquisa, teoria e } \\
\text { prática }\end{array}$ & Teorização \\
\hline Afastamento do ser pesquisado-cuidado & $\begin{array}{l}\text { Hipóteses de solução } \\
\text { Aplicação à realidade }\end{array}$ \\
\hline Análise do apreendido &
\end{tabular}

Fonte: elaborado pelas autoras 


\section{APROXIMAÇÃO COM O OBJETO DE ESTUDO E OBSERVAÇÃO DA REALIDADE: O VÍNCULO COM A COMUNIDADE}

Nessa etapa faz-se a inter-relação da motivação da pesquisa com a questão norteadora. A observação da realidade leva à tomada de consciência do problema, encaminhando para o desenvolvimento de profissionais mais sensíveis e mais críticos (BERBEL, 2014). A proximidade com a comunidade de cerca de 140 idosas, que se reúnem semanalmente com as equipes de saúde e de assistência social para o desenvolvimento de diversas atividades, ajudou a desencadear a construção de vínculo, sem o qual os extensionistas pesquisadores do Projeto de Extensão Educar para Prevenir não captariam algumas queixas das idosas, primordiais para a construção deste estudo. A inserção dos estudantes e dos docentes na comunidade participante do projeto possibilitou o presente estudo.

O problema conduziu à teorização pelo levantamento bibliográfico, com questões de pesquisa que buscaram as respostas: qual o risco de transtornos dolorosos nos pés em idosas? Como a identificação destes pode contribuir para o autoconhecimento, com impacto na prática de autocuidado? Que ações em saúde possibilitam uma maior adesão ao tratamento e prevenção de pés dolorosos?

A inserção na comunidade durante as atividades de extensão, com foco na educação em saúde, permitiu observar a realidade e captar algumas pistas sobre os problemas nos pés, a partir das quais surgiu a necessidade de trabalhar com a temática pés dolorosos. O convívio com as idosas e com as coordenadoras da saúde e da assistência social do município deram subsídios para levantar os problemas a serem investigados, conforme a segunda etapa do arco.

\section{ENCONTRO COM O SER PESQUISADO-CUIDADO E PONTOS-CHAVES}

O estudo ocorreu no ano de 2019, em uma comunidade rural, localizada na região metropolitana de Curitiba, após aprovação pelo Comitê de Ética em Pesquisa, das Faculdades Pequeno Príncipe, sob o parecer no 2.601.225.

O vínculo com a comunidade da pesquisa tornou-se um facilitador para o levantamento dos Pontos-chaves, para a teorização, além da construção de uma relação de confiança entre o grupo de trabalho do projeto de extensão e o grupo de idosas, o que trouxe segurança para o desenvolvimento da pesquisa. 
Transtornos dolorosos nos pés em idosas: pesquisa-cuidado no contexto de atividade extensionista

\section{ESTABELECIMENTO DAS CONEXÕES DE PESQUISA, TEORIA E PRÁTICA E TEORIZAÇÃO DOS TRANSTORNOS DE PÉS DOLOROSOS}

Após a identificação do problema no grupo de idosas, para contribuir na apreensão do detalhamento dos problemas, optou-se pelo uso de instrumento de pesquisa/protocolo de investigação já validado, denominado Índice Manchester de Incapacidade Associada ao Pé Doloroso no Idoso, o mais condizente com a temática levantada, o transtorno de pés dolorosos em idosas. Antes de aplicar o instrumento foi realizada uma abordagem inicial para levantar os dados sociodemográficos.

O instrumento MFPDI traduzido, adaptado e validado por Ferrari et al., (2008), consiste em 19 questões, divididas em quatro subescalas. A primeira subescala é formada por dez questões inerentes à compreensão da movimentação; a segunda é composta por cinco questões sobre a dor nos pés; a terceira por duas questões sobre a preocupação com a dor nos pés e a quarta por duas questões relacionadas à dificuldade de realizar determinado trabalho ou atividade de lazer. Em cada questão, o participante tem de apontar a frequência dos sintomas nos pés, nos últimos 30 dias. Se a incapacidade é ausente, a alternativa "nunca, em nenhum momento" (ponto =0) é assinalada. Se presente uma das alternativas "sim, em alguns dias" (ponto = 1) ou "na maioria/todos os dias" (ponto $=2$ ) deve ser escolhida. Ao utilizar estratégia de pontuação simples, somam-se todos os pontos, expressando, assim, o grau de incapacidade (GARROW et al., 2004). A pontuação do MFPDI é de 0 a 38 pontos, de forma que as maiores pontuações indicam maior grau de incapacidade.

O instrumento foi aplicado a 75 idosas, com idade igual ou superior a 60 anos, residentes em uma comunidade rural, localizada na região metropolitana de Curitiba. Os dados foram digitados em planilhas do Excel 2000 for Windows para o adequado armazenamento dos dados e, na sequência, apresentados na forma de tabelas, em frequência percentual simples para cada item do MFPDI. As idosas participantes da pesquisa foram divididas em três grupos de acordo com a faixa etária e ocupação: grupo I, faixa etária entre 60 e 69 anos, do lar; grupo II, faixa etária entre 60 e 69 anos, que trabalham fora, e grupo III, faixa etária entre 70-79 anos, do lar. Os grupos foram comparados por meio de teste $t$ independente. Os conjuntos de dados foram testados previamente para normalidade por meio do teste de Shapiro-Wilk e homogeneidade de variâncias através do teste de Levene, considerando um nível de confiança de 5\%. 


\section{AFASTAMENTO DO SER PESQUISADOR-CUIDADOR E $\quad$ SER PESQUISADO-CUIDADO}

A fase de afastamento dos pesquisadores e das participantes da pesquisa, conforme apontado pelo método, exigiu sensibilidade por parte dos pesquisadores, para indicar o término do encontro para fins de pesquisa. Conforme o indicado na pesquisa-cuidado, mesmo que o afastamento seja acordado, há circunstâncias que exigem a continuidade dos encontros, os quais podem se seguir sem o rigor de pesquisa, na condição de cuidador. $O$ contato posterior pode ser facilitado quando "o ser-pesquisador pertence ao serviço onde as informações estão sendo coletadas e em contextos de permanência dos clientes por tempo maior, como na hospitalização e cronificação" (NEVES e ZAGONEL, 2006, p.76).

\section{RESULTADOS E ANÁLISES}

A análise do apreendido, proposto pelo método de pesquisa-cuidado, e a articulação com o delineamento de hipóteses de solução e aplicação à realidade, últimas etapas do Arco de Maguerez, estão contidas nesta descrição.

Quanto ao perfil sociodemográfico da população estudada, destaca-se que a maioria, 48 (60\%), encontra-se na faixa etária de 60 a 69 anos; 39 (52\%) idosas são viúvas e 64 (85\%) não trabalham fora. Merece destaque que 72 (94\%) participantes da pesquisa se declaram alfabetizadas. Sabe-se que a escolaridade representa um fator importante, pois leva o indivíduo à leitura, onde as informações podem contribuir para a prevenção de doenças. No quesito moradia, $28(37 \%)$ participantes vivem com cônjuge/companheiro. O fato de as idosas morarem com a família pode ser um fator protetor para elas. Quanto à renda, $45(58 \%)$ pesquisadas possuem renda entre um e dois salários mínimos. Esses dados podem repercutir diretamente na condição de vida dessas idosas que, em muitos casos, se encontram em classes sociais de pobreza ou extrema pobreza e, muitas vezes, são mantenedoras de famílias.

Para a análise quanto às frequências absolutas e porcentuais do Índice de Manchester de incapacidade associada ao pé doloroso no idoso, as participantes foram agrupadas da seguinte forma: Idosas do lar com idades entre 60 e 69 anos (Grupo I); idosas da mesma faixa etária e que trabalham fora (Grupo II) e idosas com idades entre 70 e 79 anos do lar (Grupo III). Na primeira categoria (compreensão da movimentação), a maioria das participantes não tem problema ao caminhar fora de casa, pois caminham por longa distância sem dificuldade, mas de forma mais vagarosa. Evitam andar sobre superfícies ásperas ou irregulares e ficar de pé por muito tempo. 
Transtornos dolorosos nos pés em idosas: pesquisa-cuidado no contexto de atividade extensionista

Na segunda categoria (dor nos pés), a maioria relata não sentir dores constantes nos pés; a minoria das participantes alega ter dor nos pés pela manhã. Na terceira categoria (preocupação com a dor nos pés) merece destaque que a maioria das pesquisadas tem preocupação com relação aos pés e aos sapatos que precisam calçar. $\mathrm{Na}$ última categoria (dificuldade), quando perguntado sobre conseguir realizar o trabalho que faziam antes, a resposta foi afirmativa e, quanto ao lazer, as idosas do grupo II alegam que praticam o lazer, enquanto nos outros dois grupos as participantes declaram dificuldade de praticar as atividades de lazer alguns dias.

Na comparação dos três grupos por meio do MFPDI, o grupo III apresenta valor médio maior de MFPDI $(18,48)$ em relação aos demais grupos ( $I=16,58$ e $I I=17,90)$. As comparações dos grupos 2 a 2 por meio do teste $t$ não indicam diferenças significativas (grupo I x II teste $t$. 0,50; p: 0,62; grupo I x III teste t. -1,1; p: 0,27).

O processo de envelhecimento é marcado por modificações fisiológicas e patológicas ocasionando mudanças físicas, psicológicas e sociais. Ocorrem alterações nas estruturas anatômicas e fisiológicas em todo organismo, inclusive nos pés. Estas modificações ocasionam alteração postural podendo levar a quedas, decréscimo do número de fibras musculares e do tecido adiposo dos pés. A pele tende a ficar mais seca e perde a elasticidade, o coxim plantar fica diminuído. (MENZ et al., 2005). Ainda segundo Ferreira, Portella e Dorin (2018), as alterações podológicas, quando instaladas no processo de envelhecer, para algumas pessoas vêm acompanhadas da diminuição da funcionalidade e do aumento do grau de dependência de cuidadores para o desenvolvimento das atividades diárias, o que pode ser agravado na presença de doenças crônicas e incapacitantes. Isso ocasiona problemas de saúde, destacando-se os que acometem as estruturas do aparelho locomotor como ossos, músculos, articulações, nervos e tendões, os quais se agravam na presença da dor.

No Brasil, a saúde do idoso aparece como uma das prioridades das políticas públicas, principalmente no que se refere à manutenção da autonomia e independência (MARIN e MACIEL, 2014). Sabe-se, entretanto, que as alterações funcionais realizam importante papel nessa condição. Mesmo assim, muitos problemas apresentados pelos idosos não são muito valorizados, tanto pelos profissionais de saúde como pelo próprio idoso, como, exemplo, citamse as alterações nos pés.

Os cuidados com os pés favorecem o nível de atividade praticada e, consequentemente, diminuem a dor e a rigidez articular associada às doenças degenerativas da articulação, além de melhorar o controle glicêmico (KELECHI, 1996 apud MARIN e MACIEL, 2012 p. 244), sendo aspecto de grande importância para a promoção da saúde dessas pessoas (STOLT et al., 2012). 
Transtornos dolorosos nos pés em idosas: pesquisa-cuidado no contexto de atividade extensionista

Para a execução dos movimentos, a manutenção do equilíbrio e a postural corporal são fundamentais. Os pés são coordenados ao sistema muscular e impelem informações sensoriais sobre a posição do corpo por meio de mecanorreceptores na região plantar. Ainda, em contato com o solo, adaptam-se às suas irregularidades durante a marcha, colaborando para a absorção do impacto durante a caminhada (PRATO et al., 2012).

Encontram-se entre os problemas funcionais dos pés as alterações anatômicas e fisiológicas, que podem ser advindas de doenças sistêmicas, de desordens da marcha e traumatismos nos pés que danificam a integridade das unhas, da pele, dos nervos, dos vasos e das estruturas ósseas (FERRARI et al., 2009; SILVA, SANTO; CHIBANTE, 2017). Tais agravos originam para a vida do idoso algumas implicações, tais como a diminuição na desenvoltura para executar atividades cotidianas, diminuição da força, do equilíbrio, da mobilidade, alterações na marcha, aumento do risco de quedas e da instabilidade postural resultando em incapacidade funcional. (PRATO et al., 2012).

Nos idosos há um decréscimo no número de mecanorreceptores encontrados nos pés e há um acréscimo no limiar de excitabilidade vibratória e cutânea. A sensibilidade plantar é uma fonte admirável de informação para o domínio do equilíbrio, pois agrega as mudanças de pressão sob o pé especialmente durante a marcha. Com a chegada dessas informações ao sistema nervoso central, sobre a posição do corpo, são gerados reflexos posturais para a manutenção da posição vertical. No entanto, com o avançar da idade, as agilidades do controle postural são modificadas e assim a velocidade das informações e o processamento das respostas são mais lentas e inadequadas propiciando possíveis quedas. (AIKAMA et al., 2009).

A partir do exposto propõem-se hipóteses de solução e estratégias de aplicação à realidade, como formas de promover educação em saúde nas comunidades.

\section{EDUCAÇÃO EM SAÚDE: FORMAS DE PROMOVER SAÚDE}

Diversas podem ser as hipóteses de solução levantadas, quando se trata de promover educação em saúde. No entanto, destaca-se que as hipóteses que encaminham para boas práticas e aplicação à realidade estudada são as que condizem com o perfil do grupo participante do estudo. Não se trata, portanto, de generalizar hipóteses ou ações, e sim de buscar as que são praticamente suscitadas pela cultura e pelas características do grupo em questão. É exatamente este o desafio do projeto de extensão, o que justifica a escolha pela pesquisa-cuidado pelo uso da problematização com o Arco de Maguerez. 
Transtornos dolorosos nos pés em idosas: pesquisa-cuidado no contexto de atividade extensionista

As hipóteses mais adequadas para este caso foram: desenvolver um manual de autocuidado com cuidados especiais com os pés, produzido em linguagem simples, adequada para o perfil do grupo de idosas; promover atividades de esclarecimentos e conscientização sobre a temática; promover saúde pelo ritual de lava-pés.

Pelo perfil e características das participantes do estudo, percebeu-se que estas teriam facilidade para aderir ao ritual de lava-pés, o qual pode ser compreendido, primeiramente, como uma mensagem dos participantes do projeto de extensão Educar para Prevenir, profissionais e futuros profissionais de saúde, que estão ali para compreender a realidade, aproximar-se ao máximo dela e servir à comunidade. Essa mensagem tornou-se um forte componente fortalecedor do vínculo da equipe com a comunidade.

O rito seguiu da seguinte forma: 1- Foram convidadas 12 senhoras para sentar-se em cadeiras que foram expostas à frente; 2- A seguir, uma equipe do projeto iniciou o ritual que foi adaptado para a orientação sobre saúde. Assim, concomitantemente com a lavagem dos pés que foi feita uma a uma, seguida da secagem, foi utilizado creme hidratante e realizada a massagem nos pés; 3 - Enquanto seguiu-se o ritual que demonstrou o cuidado com os pés, lentamente, foi realizada orientação por uma especialista, em roda de conversa, de acordo com as dúvidas que surgiram. Foram proferidas informações pertinentes sobre a correta higiene e hidratação dos pés, sem esquecer os cuidados quanto à higiene, com os sapatos, bem como quanto à escolha adequada dos mesmos. As próprias participantes idosas resgataram muitos dos seus conhecimentos e partilharam com as demais.

O sentido do ritual de lava-pés foi discutido e ressignificado para a atividade sobre pés dolorosos, evidenciando-se forte mensagem do ritual, de prestar serviço, ser solidário e saber ouvir - isso por parte da equipe de saúde e por parte da comunidade -, ser hospitaleiro e saber acolher.

\section{CONSIDERAÇÕES FINAIS}

A aplicação do instrumento de pesquisa foi uma estratégia importante para a identificação da compreensão da movimentação, indicação e preocupação com a dor nos pés e dificuldade de locomoção das idosas. Constata-se que maioria das participantes não tem problema ao caminhar; relata não sentir dores constantes nos pés; não se preocupa com as dores nos pés e as idosas que ainda trabalham fora não têm dificuldade quanto à prática do lazer.

Evidencia-se que a incapacidade funcional dos pés nas participantes da pesquisa é baixa, demonstrando que a dor nos pés, como citada pela minoria, não causa dependência funcional 
Transtornos dolorosos nos pés em idosas: pesquisa-cuidado no contexto de atividade extensionista

para a realização dos trabalhos diários. Portanto, o fator determinante para este resultado pode ser a comunidade escolhida para o estudo, ou seja, as pesquisadas habitam a zona rural com hábitos e estilos de vida mais ligados à natureza.

Pode-se considerar que o estudo favorece a identificação dos problemas podais, que podem estar implicados no decréscimo da habilidade para executar atividades cotidianas e perda do equilíbrio, o que pode levar ao aumento do risco de quedas

Com relação à temática proposta, os elementos levantados pela pesquisa-cuidado e as atividades educacionais, executadas pelos extensionistas, foram primordiais para o desenvolvimento e a aplicação da proposta, por meio da utilização do Arco de Maguerez.

O ritual de lava-pés proporcionou os esclarecimentos e conscientização sobre a temática com êxito. Entretanto, a atividade de elaboração de um manual sobre os cuidados especiais com os pés não teve o desfecho proposto, visto que não foi apresentado à comunidade pesquisada. $O$ manual foi desenvolvido, pelos extensionistas, mas em virtude do surgimento da pandemia, causada pelo vírus SARS-CoV-2 no início do ano de 2020, houve a suspensão de todas as atividades presenciais impedindo a finalização desta atividade.

O estudo também evidencia a necessidade de promover a saúde por meio da educação em saúde de qualidade, que permita a participação e o protagonismo da comunidade. Neste sentido, quando a tríade ensino, pesquisa e extensão ocorre de forma integrada, a compreensão da realidade por meio da pesquisa é instrumentalizada de maneira mais efetiva, pois propicia o trabalho de educação em saúde na comunidade.

\section{REFERÊNCIAS}

AIKAWA, Adriana Correa et al. Estudo correlacional do pé geriátrico com requisitos cinéticofuncionais. Fisiot Mov, v. 22, p. 3, p. 395-405, 2009. Acesso: 30 jun. 2018. Disponível em: periódicos. pucpr.br/index.php/fisio/article/viewFile/19467/18809.

BERBEL, Neusi Aparecida Navas. Metodologia da problematização: respostas de lições extraídas da prática. Semina: Ciências Sociais e Humanas, Londrina, v. 35, n. 2, p. 61-76, jul./dez. 2014. Acesso: 27 set. 2018. Disponível em: file:///C:/Users/User/Downloads/18193-98624-1PB\%20(1).pdf.

COUTO, Giovanna Riccitelli do et al. Síndrome do pé doloroso na população idosa. Rev Bras Geriatr Gerontol, Rio de Janeiro, v. 8, n. 1, p. 72-76. 2014. Acesso: 22 out. 2021. Acesso: 22 mai. 2018. Disponível em: file://C:/Users/User/Downloads/v8n1a12\%20(8).pdf.

DAMACENO, Maria José Caetano Ferreira; CHIRELLI Mara Quaglio. Implementação da Saúde do Idoso na Estratégia Saúde da Família: visão dos profissionais e gestores. Ciênc. saúde colet., v. 24, n. 5, p. 1637-1646, 2019. Acesso: 22 out. 2021. Disponível em: https://www.scielosp.org/pdf/csc/2019.v24n5/1637-1646/pt 
FERNANDES, Maria da Graça Melo et al. Avaliação do medo de cair em idosos em atendimento ambulatorial. Rev Enferm UFPE on line [periódico na Internet]. 2013. Acesso: 10 set. 2018.2 Disponível em: file:///C:/Users/User/Downloads/AVALIAODOMEDODECAIREMIDOSOSEMATENDI MENTOAMBULATORIAL.pdf.

FERRARI, Sabrina Canhada et al. Patologias no pé do idoso. Rev Bras Ciênc Envelh Hum, v. 6, n. 1, p. 106-18, 2009. Acesso: 10 set. 2018. Disponível em: http://seer.upf.br/index.php/rbceh/article/view/735/485.

FERRARI, Sabrina Canhada et al. Índice Manchester de Incapacidade Associada ao Pé Doloroso no Idoso - Tradução, Adaptação Cultural e Validação para a Língua Portuguesa. Rev Bras Reumatol, v. 48, n.6, p. 335-341, nov./dez., 2008. Acesso: 10 set. 2018. Disponível em: http://www.scielo.br/pdf/rbr/v48n6/06.pdf. Acesso: 10 ago. 2018.

FERREIRA, Eidimara; PORTELLA, Marilene Rodrigues; DORING Marlene. Alterações dos pés de idosos institucionalizados. Rev. bras. geriatr. gerontol., v. 21, n. 03, p. 363-370, 2018. Acesso: 22 de outubro de 2021. Disponível em:

https://www.scielo.br/j/rbgg/a/wtsY8hLK5YqGqs4StkWDtjz/?lang=pt\&format=pdf

FREIRE, Paulo. Conscientização: Teoria e Prática da Libertação. 3 ed. São Paulo: Moares, 1980.

GARROW, Adam; SILMAN, Alam; MACFARLANE, G.ary. The Cheshire foot pain and disability survey: a population survey assessing prevalence and associations. Pain, v. 110, p. 37884, 2004. Acesso: 27 set. 2018. Disponível em: file://C:/Users/User/Downloads/garrow2004.pdf\%20\%20associations.pdf.

GORECKI G. A. Shoe related foot problems and public health. J Am Podiatry Assoc, v. 68, n. 4, p. 245-7, 1978.

MARIN, Maria José Sanches; MACIEL, Mateus de Carvalho. Caracterização dos problemas relacionados aos pés de idosos de uma comunidade em município do interior do Estado de São Paulo. Rev Bras Geriatr Gerontol, Rio de Janeiro, v. 17, n. 2, p. 243-253, 2014. Acesso: 27 set. 2018. Disponível: http://www.scielo.br/pdf/rbgg/v17n2/1809-9823-rbgg-17-02-00243.pdf.

MARQUES, Marilia Braga et al. Intervenção educativa para a promoção do autocuidado de idosos com diabetes mellitus. Rev Esc Enferm USP. v. 53, p. 1-9, 2019. Acesso: 22 out. 2021. Disponível em: https://www.scielo.br/j/reeusp/a/gs7Q8rTDjhL3CLsKPCQHnTj/?format=pdf\&lang=pt

MENZ, Hylton B.; MORRIS, Meg. E.; LORD, Stephen R. Foot and ankle characteristics associated with impaired balance and functional ability in older people. J Gerontol A Biol Sci Med Sci, v. 60, n. 12, p. 1546-52, 2005. Acesso: 27 set. 2018. Disponível em: file:///C:/Users/User/Downloads/menz2005.pdf\%20Foot\%20and\%20Ankle.pdf.

MORIN, Edgard. Os sete saberes necessários à educação do futuro. São Paulo: Cortes; Unesco, 2001.

NEVES, Eloita Pereira; ZAGONEL, Ivete Palmira Sanson. Pesquisa-cuidado: uma abordagem metodológica que integra pesquisa, teoria e prática em enfermagem. Cogitare Enferm., v.11, n.1, 
p.73-79, 2006. Acesso: 27 set. 2018. Disponível em: file://C:/Users/User/Downloads/598014677-1-PB\%20(2).pdf.

OGRADOWSKI, Karin Rosa Persegona et al. Uso da metodologia da problematização e ensino da bioética: aprendizagem ativa e significativa In: RAULI, Patrícia Maria Forte et al. (Orgs). Bioética e Metodologias Ativas no Ensino Aprendizagem serie Bioética v. 7. Curitiba: CRV, 2018, p. $49-62$.

PRATO, Sabrina Canhada Ferrari; SANTOS, Fânia Cristina; TREVISAN, Virgínia Fernandes Moça. Pé doloroso do idoso associado à incapacidade funcional. Rev Dor. v. 13, n. 1, p. 18-24, 2012. Acesso: 22 mai. 2018. Disponível: http://www.scielo.br/pdf/rdor/v13n1/a04v13n1.

SILVA, Joziane Santos; SANTO Fátima Helena do Espírito; CHIBANTE Carla Lube de Pinho. Alterações nos pés do idoso hospitalizado: um olhar cuidadoso da enfermagem. Esc Anna Nery, v. 21, n. 1, p. 1-7, 2017. Acesso: 22 out. 2021. Disponível em: https://www.scielo.br/j/ean/a/wc'TcB4RLNksN5LTtfKMfRhb/?lang=pt\&format=pdf

SILVA, Teodoro Marcelino; SANTOS, Rosely Leyliane. Prevenir é o melhor remédio: Experiência da Avaliação Clínica dos Pés em Idosos Diabéticos. Braz. J. Hea. Rev., Curitiba, v. 3, n. 5, p. 73423-73434 set./out. 2020. Acesso: 27 out. 2021. Disponível em: file://C:/Users/Acer/Downloads/17490-45079-1-PB\%20(1).pdf

STOLT, Minna et al. Foot health and selfcare activities of older people in home care. J Clin Nurs, v. 21 n. 21-22, p. 3082-95, 2012. Acesso: 27 set. 2018. Disponível em: file://C:/Users/User/Downloads/stolt2012.pdf\%20\%20Foot\%20health\%20and.pdf.

TAVARES, Darlene Mara dos Santos; DIAS, Flavia Aparecida. Capacidade funcional, morbidades e qualidade de vida de idosos. Texto Contexto Enferm, v. 21, n. 1, p. 112-20. 2012. Acesso: 27 set. 2018. Disponível em: http://www.scielo.br/pdf/tce/v21n1/en_a13v21n1.pdf.

ZAGONEL, Ivete Palmira Sanson et al. Pesquisa-cuidado: da teoria à prática. In: LACERDA, Maria Ribeiro; COSTENARO, Regina Santini (Org.). Metodologias de pesquisa para a enfermagem e saúde: da teoria à prática. Porto Alegre: Moriá, 2016, p. 215-249.

Recebido em: 29/06/2021

Aceito em: 24/11/2021 